\title{
Solid-state metathesis reactions under pressure: A rapid route to crystalline gallium nitride
}

\author{
Charles H. Wallace, Sang-Ho Kim, Garry A. Rose, Lin Rao, James R. Heath, \\ Malcolm Nicol, and Richard B. Kaner ${ }^{\mathrm{a}}$
}

(Received 20 October 1997; accepted for publication 7 December 1997)

\begin{abstract}
High pressure chemistry has traditionally involved applying pressure and increasing temperature until conditions become thermodynamically favorable for phase transitions or reactions to occur. Here, high pressure alone is used as a starting point for carrying out rapid, self-propagating metathesis reactions. By initiating chemical reactions under pressure, crystalline phases, such as gallium nitride, can be synthesized which are inaccessible when initiated from ambient conditions. The single-phase gallium nitride made by metathesis reactions under pressure displays significant photoluminescence intensity in the blue/ultraviolet region. The absence of size or surface-state effects in the photoluminescence spectra show that the crystallites are of micron dimensions. The narrow lines of the x-ray diffraction patterns and scanning electron microscopy confirm this conclusion. Brightly luminescent thin films can be readily grown using pulsed laser deposition.

(C) 1998 American Institute of Physics. [S0003-6951(98)03705-X]
\end{abstract}

Gallium nitride $(\mathrm{GaN})$ is important to the optoelectronics industry since thin films can be used to fabricate $p$ - $n$ junctions, quantum wells, lasers, and displays in the blue/ ultraviolet region. ${ }^{1-4}$ Light emitting diodes made with $\mathrm{GaN}$ are significantly brighter than conventional light bulbs and are up to 60 times brighter than the best known gallium phosphide materials. ${ }^{1,3}$ Polycrystalline GaN may find use as a blue phosphor in display applications. GaN has generally been formed by heating $\mathrm{Ga}, \mathrm{Ga}_{2} \mathrm{O}_{2}$, or gallium halides at elevated temperatures $(>750 \mathrm{~K})$ in an ammonia atmosphere for extended periods. ${ }^{5-8}$ The materials produced are often poorly crystalline, contain impurities, and/or show weak photoluminescence. Other recent synthetic methods use polymeric and single-source precursors, microwave heating, and plasma assisted nitridation. ${ }^{9-13}$ Single crystals of GaN are generally grown under high temperature (1700-1800 K)/ high pressure conditions ( $>2 \mathrm{GPa}$ for $\sim 20 \mathrm{~h}$ ) since $\mathrm{GaN}$ decomposes at $\sim 1150 \mathrm{~K}$ under ambient pressure. ${ }^{14-16} \mathrm{Re}-$ cent experiments indicate sodium fluxes can be useful for crystal growth. ${ }^{17}$

Solid-state metathesis (SSM) reactions have developed over the past several years into an effective rapid method for producing materials such as nitrides that are difficult to make using conventional techniques. ${ }^{18-20}$ Formation of very stable salt by-products drives these highly exothermic reactions. In contrast, elemental self-propagating high temperature synthesis (SHS) reactions are driven solely by product formation which for $\mathrm{GaN}$ synthesis $\left(\mathrm{Ga}+1 / 2 \mathrm{~N}_{2}, \Delta \mathrm{H}_{\mathrm{rxn}}\right.$ $=-110 \mathrm{~kJ} / \mathrm{mol}$ ) represents only $21 \%$ of the energy available in a comparable SSM reaction (e.g., $\mathrm{GaI}_{3}+\mathrm{Li}_{3} \mathrm{~N}, \Delta \mathrm{H}_{\mathrm{rxn}}=-515 \mathrm{~kJ} / \mathrm{mol}$ ). The intense heat of SSM reactions initiated from $298 \mathrm{~K}$ often generates temperatures of $>1500 \mathrm{~K}$ (typically in $<1 \mathrm{~s}$ ) and has even yielded some high pressure/high temperature nitride phases such as cubic TaN. ${ }^{21}$ Cubic TaN is normally made at more than 1900 $\mathrm{K}$ and $16 \mathrm{MPa}$ of nitrogen pressure. ${ }^{22}$ When carrying out a

${ }^{a}$ Author to whom correspondence should be addressed: Department of Chemistry and Biochemistry, University of California, Los Angeles, CA 90095-1569; electronic mail: kaner@chem.ucla.edu
SSM reaction between $\mathrm{TaCl}_{5}$ and $\mathrm{Li}_{3} \mathrm{~N}$ [Eq. (1)] under ambient conditions, the product observed is the subnitride, $\mathrm{Ta}_{2} \mathrm{~N}$, rather than nitrogen rich $\mathrm{TaN}$

$$
\mathrm{TaCl}_{5}+5 / 3 \mathrm{Li}_{3} \mathrm{~N} \rightarrow \mathrm{TaN}+5 \mathrm{LiCl}+1 / 3 \mathrm{~N}_{2} .
$$

Adding 12 moles of $\mathrm{NaN}_{3}$ to this reaction increases the nitrogen overpressure enough to form some high temperature/ high pressure cubic TaN along with the expected hexagonal $\mathrm{Ta}_{2} \mathrm{~N} .{ }^{20}$ Recent experiments carried out under $4.5 \mathrm{GPa}$ of pressure without $\mathrm{NaN}_{3}$ demonstrate that cubic $\mathrm{TaN}$ can be produced directly as the major product. The maximum adiabatic reaction temperature $\left(T_{\mathrm{ad}}\right)$ achieved if all the enthalpy of this reaction is used to heat the products at constant pressure is $1681 \mathrm{~K}$ which is less than the $1900 \mathrm{~K}$ normally required to form cubic TaN. Therefore, applying pressure to SSM reactions can lead directly to high pressure/high temperature phases.

The synthesis of cubic TaN suggests that other nitrides could also be made using SSM reactions under appropriate pressures from metal halides and $\mathrm{Li}_{3} \mathrm{~N}$. Unfortunately, reactions between gallium halides and $\mathrm{Li}_{3} \mathrm{~N}$ fail under ambient conditions even though they are very favorable thermodynamically $(>500 \mathrm{~kJ} / \mathrm{mol}) .{ }^{23}$ Therefore, these reactions appear to be good candidates for synthesis under pressure.

To carry out SSM reactions under pressure a Bridgmananvil cell, whose essential features are shown in Fig. 1, is used. A fine $(0.15 \mathrm{~mm})$ iron wire is threaded through a mixture of reactants and pre-compacted into a pellet (typically $4.8 \mathrm{~mm}$ diameter, $1.5 \mathrm{~mm}$ high, $\sim 80 \mathrm{mg}$ ). An Inconel gasket is coated with an insulating alumina/magnesia paste, affixed to the bottom anvil and cured. The pellet is placed in the gasket and the top Bridgman anvil is placed above the sample aided by alignment guides (not shown). Copper leads are placed in contact with the electrically conducting tungsten carbide cores and held in place with thin sheets $(2 \mathrm{~mm})$ of polyvinyl chloride. This entire assembly, along with a calibrated load cell to monitor pressure by measuring the applied force, is placed in a hydraulic press which can generate pressures up to $10 \mathrm{GPa}$. After increasing the pressure, the reaction is initiated by passing a current through the an- 


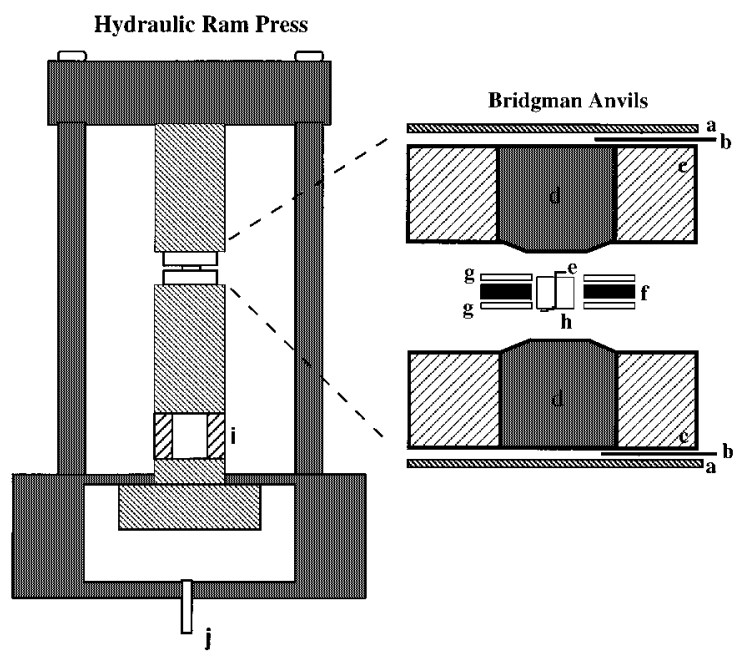

FIG. 1. A schematic diagram of the hydraulic press and the Bridgman anvils used for high pressure SSM reactions. The components include: (a) PVC sheets used for electrical insulation, (b) copper leads to pass current, (c) Bridgman anvils, (d) tungsten carbide cores, (e) iron wire for ignition of precursors, (f) Inconel gasket for lateral containment of reactants, (g) alumina/magnesia for electrical insulation, (h) solid reactants pre-pressed into a pellet, (i) strain gauge, and (j) inlet for hydraulic fluid.

vils, via the copper leads, which resistively heats the iron wire. The reaction time from ignition through propagation to completion is less than $1 \mathrm{~s}$. After releasing the pressure, the products are collected and salt by-products washed away with alcohol and/or water. The volume of reactants can readily be increased in order to form bulk quantities of the desired material. For example, a modified belt apparatus with an internal cell volume of $0.48 \mathrm{~cm}^{3}(\sim 1.4 \mathrm{~g}$ of reactants) has been used to obtain $\sim 300 \mathrm{mg}$ of $\mathrm{GaN}$ per reaction. Greater quantities can be synthesized by increasing the volume of the cell. Note that cubic boron nitride and diamond are produced commercially on a megaton scale each year using large volume presses. ${ }^{24}$

The reaction between $\mathrm{GaI}_{3}$ and $\mathrm{Li}_{3} \mathrm{~N}$ produces $\mathrm{GaN}$ as given in Eq. (2)

$$
\mathrm{GaI}_{3}+\mathrm{Li}_{3} \mathrm{~N} \rightarrow \mathrm{GaN}+3 \mathrm{LiI} .
$$

This reaction is driven by salt formation $\left(\Delta \mathrm{H}_{\mathrm{RXN}}=-515 \mathrm{~kJ} / \mathrm{mol}\right)$ which accounts for $79 \%$ of the heat released. Assuming complete reaction and adiabatic conditions, a maximum reaction temperature, $T_{\mathrm{ad}}$, of $1443 \mathrm{~K}$ is calculated. Since this temperature is above the melting point of lithium iodide $(722 \mathrm{~K})$, the reaction is expected to readily propagate ${ }^{18}$ Differential scanning calorimetry indicates that the reaction of $\mathrm{GaI}_{3}$ and $\mathrm{Li}_{3} \mathrm{~N}$ initiates at $503.7 \mathrm{~K}$, where a large irreversible exotherm is found. Other gallium halides could be used to produce $\mathrm{GaN}$ including $\operatorname{GaBr}_{3}\left(\Delta \mathrm{H}_{\mathrm{RXN}}=-611 \mathrm{~kJ} / \mathrm{mol}, \quad T_{\mathrm{ad}}=1593 \mathrm{~K}\right), \quad \mathrm{GaCl}_{3}$ $\left(\Delta \mathrm{H}_{\mathrm{RXN}}=-645 \quad \mathrm{~kJ} / \mathrm{mol}, \quad T_{\mathrm{ad}}=1656 \quad \mathrm{~K}\right)$ or $\mathrm{GaF}_{3}$ $\left(\Delta \mathrm{H}_{\mathrm{RXN}}=-627 \mathrm{~kJ} / \mathrm{mol}, T_{\mathrm{ad}}=1954 \mathrm{~K}\right)$. Warning: Unfortunately, these gallium halides ( $\mathrm{GaBr}_{3}, \mathrm{GaCl}_{3}$ and $\mathrm{GaF}_{3}$ ) spontaneously detonate on mixing with lithium nitride which makes them unsuitable for pressing into pellets needed for carrying out reactions under pressure.

Under ambient conditions, the reaction of $\mathrm{GaI}_{3}$ and $\mathrm{Li}_{3} \mathrm{~N}$ produces a small amount of poorly crystalline GaN (Fig. 2, top) along with gallium metal (visible as gallium spheres), Downloaded 19 May 2006 to 131.215.225.175. Redistribution subject

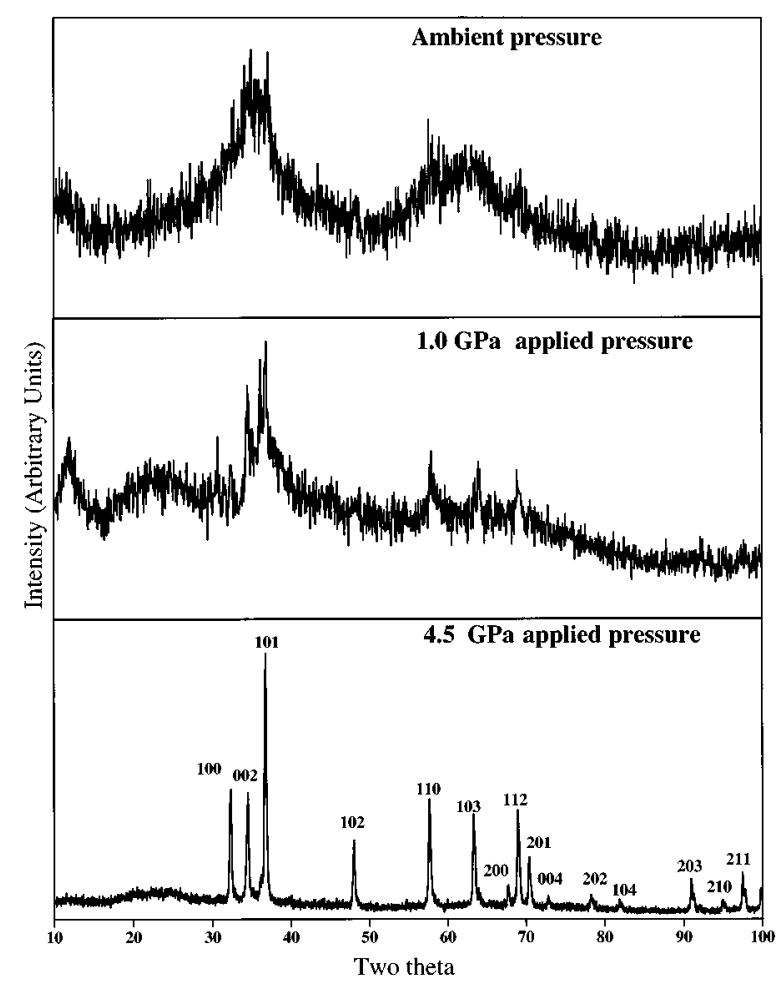

FIG. 2. Powder x-ray diffraction patterns of the washed product formed from the reaction of $\mathrm{GaI}_{3}$ and $\mathrm{Li}_{3} \mathrm{~N}$ under ambient conditions (top), with 1 $\mathrm{GPa}$ (middle), and with $4.5 \mathrm{GPa}$ of applied pressure (bottom). The Miller indices for hexagonal $\mathrm{GaN}$ are indicated above the crystalline diffraction peaks.

nitrogen gas, and lithium iodide. At higher pressures, both the crystallinity and yield of GaN increases. At $1 \mathrm{GPa}$ partially crystalline $\mathrm{GaN}$ forms (Fig. 2, middle). The reaction appears complete with little evidence of Ga metal formation. Increasing the pressure to $4.5 \mathrm{GPa}$ leads to highly crystalline $\mathrm{GaN}$ (Fig. 2, bottom). A least squares refinement of the x-ray data indicates that $a=3.188(4) \AA$ and $c=5.18(1) \AA$, which is comparable to literature values for hexagonal $\mathrm{GaN}$ of $a$ $=3.1879-3.1894 \AA$ and $c=5.1856-5.1865 \AA .25$ The LiI is removed by washing with water and yields of $\mathrm{GaN}$ of up to $87 \%$ are obtained. Losses are simply due to handling the material. The GaN produced by the $4.5 \mathrm{GPa}$ metathesis reaction is single phase, according to the $\mathrm{x}$-ray powder diffraction pattern and contains no detectable iodine by energy dispersive spectroscopy. The $\mathrm{Ga}$ content of the $\mathrm{GaN}$ is 51 mol \% (50\% expected) as calculated by thermal gravimetric analysis carried out in air to $1273 \mathrm{~K}$, which converts all of the $\mathrm{GaN}$ to $\mathrm{Ga}_{2} \mathrm{O}_{3}$. X-ray photoelectron spectroscopy indicates the presence of some surface oxidation which can be reduced by washing with nonaqueous solvents or by a brief plasma nitridation. ${ }^{13}$

The high quality of the GaN produced by metathesis under 4.5 GPa confining pressure is apparent in the photoluminescence spectra shown in Fig. 3. The excitation source is $5 \mathrm{~ns}, 20 \mu \mathrm{J}$ pulse of $266 \mathrm{~nm}$ radiation. The room temperature (300 K) spectrum (Fig. 3, bottom) reveals only the 3.38(3) $\mathrm{eV}$ band gap characteristic of bulk GaN. ${ }^{26}$ The low temperature (20 K) spectrum (Fig. 3, middle) is also consistent with high quality bulk $\mathrm{GaN}$ with a sharp excitonic transition at $3.45(3) \mathrm{eV}$ and lower energy features originating from to AIP license or copyright, see http://apl.aip.org/apl/copyright.jsp 


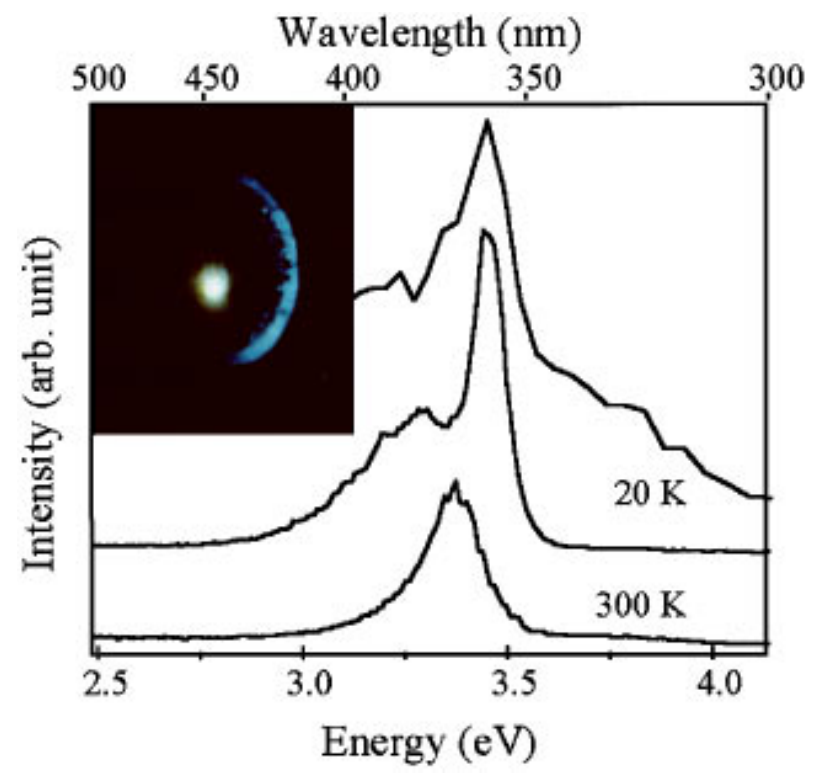

FIG. 3. Gated photoluminescence spectra of GaN produced by metathesis reactions carried out under $4.5 \mathrm{GPa}$ of pressure. The room temperature (300 K) spectrum (bottom) exhibits the band gap of bulk $\mathrm{GaN}$ at $3.38(3) \mathrm{eV}$, while the lower temperature $(20 \mathrm{~K})$ spectrum (middle) has a sharp excitonic transition at 3.45(3) eV and emission due to donor-acceptor pair recombination at lower energies. The $20 \mathrm{~K}$ spectrum (top) is from a GaN film grown on a $\mathrm{MgO}$ substrate by pulsed laser deposition. The bright blue photoluminescence from the GaN film can be seen in the photograph.

known donor-acceptor pair recombination. ${ }^{27}$ The photoluminescence measurements do not show either size effects or surface states, consistent with micron-scale, rather than nano-scale, crystallites. This is confirmed by scanning electron microscopy and a negligible amount of line broadening measured in the x-ray diffraction pattern (Fig. 2, bottom) when compared to an external silicon standard.

To demonstrate the potential for device fabrication, pulsed laser deposition of the powder was used to grow thin polycrystalline $\mathrm{GaN}$ films on $\mathrm{MgO}$ substrates. ${ }^{28} \mathrm{~A}$ pressed pellet of $\mathrm{GaN}$ powder was used as a rotating target in a vacuum chamber with a pressure $\leqslant 5 \times 10^{-8}$ Torr during growth. The target was pre-ablated to remove any surface contaminants. A $150 \mathrm{~mJ}$ pulsed excimer laser $(248 \mathrm{~nm})$ with a fluence of $\sim 2 \mathrm{~J} / \mathrm{cm}^{2}$ at a pulse repetition rate of $1 \mathrm{~Hz}$ for $4 \mathrm{~h}$ enables films of $800 \AA$ thickness to be grown on a $\mathrm{MgO}$ substrate heated to $580{ }^{\circ} \mathrm{C}$. The bright blue photoluminescence (Fig. 3, upper left) is a secondary reflection from the $\mathrm{GaN}$. The white spot is the primary, bright reflection and has bleached the photographic film. Although the high energy pulsed laser caused irreversible damage to the thin film after 1000 laser shots, the photoluminescence spectrum (Fig. 3, top) reveals the signature of $\mathrm{GaN}$ with a good signal to noise ratio. Work on creating thin film devices with doped $\mathrm{GaN}$ is now in progress.

An equilibrium phase diagram for $\mathrm{GaN}$ suggests that at the calculated adiabatic temperature of $1443 \mathrm{~K}$, below a pressure of $4 \mathrm{MPa}$, the formation of Ga plus nitrogen gas should be favorable relative to GaN. ${ }^{14}$ However, above $4 \mathrm{MPa} \mathrm{GaN}$ is stable, in agreement with the observed SSM results under pressure. Inert additives such as salt have been used to lower the temperatures of other SSM reactions, leading to less crystalline products. ${ }^{20}$ For the $\mathrm{GaI}_{3} / \mathrm{Li}_{3} \mathrm{~N}$ reaction, salt additives are of interest not only to lower reaction temperatures and Downloaded 19 May 2006 to 131.215 .225 .175 . Redistribution subject product crystallinity, but potentially at lower temperature, reactions could be developed to produce $\mathrm{GaN}$ at lower pressures. In theory, addition of 6.2 or more moles of $\mathrm{LiCl}$ should lower the reaction temperature enough $(\leqslant 940 \mathrm{~K})$ to favor the formation of GaN under ambient pressure. However, this may simply lead to nanocrystalline $\mathrm{GaN}$, as observed in metathesis reactions between $\mathrm{GaCl}_{3}$ and $\mathrm{Li}_{3} \mathrm{~N}$ carried out in an autoclave with benzene at $553 \mathrm{~K}^{29}$

The cell designed for igniting reactions under pressure can now be used for carrying out other SSM reactions. Since high quality mixed-metal solid solutions have been made by SSM reactions under ambient conditions, ${ }^{30}$ experiments to produce GaN solid solutions, such as $(\mathrm{Ga}, \mathrm{Al}, \mathrm{In}) \mathrm{N}$ from appropriate mixed-metal halide precursors are in progress. Recent work on another SSM reaction suggests that other high temperature/high pressure phases such as cubic boron nitride can be synthesized under appropriate conditions. ${ }^{31}$

This work was supported by the National Science Foundation, the University of California Campus Laboratory Collaboration Program (M.N., R.B.K.), along with Guggenheim (R.B.K.), Packard, and Sloan (J.R.H., R.B.K.) Fellowships.

1 “Nitride News"' Compound Semiconductors 2, 3 (1996).

${ }^{2}$ I. Adasaki, H. Amano, N. Koide, M. Kotaki, and K. Manabe, Physica B 185, 428 (1993).

${ }^{3}$ G. Fasol, Science 272, 289 (1996).

${ }^{4}$ R. L. Aggarwal, P. A. Maki, R. J. Molnar, Z.-L. Liau, and I. Melngailis, J. Appl. Phys. 79, 4 (1996).

${ }^{5}$ A. Addamiano, J. Electrochem. Soc. 108, 1072 (1961).

${ }^{6}$ D. Elwell and R. S. Feigelson, J. Cryst. Growth 66, 45 (1984).

${ }^{7}$ C. M. Balkas and R. F. Davis, J. Am. Ceram. Soc. 79, 9 (1996).

${ }^{8}$ R. Dwilinski, A. Wysmolk, J. Baranowski, M. Kaminska, R. Doradzinski, J. Gorczynski, L. Sierzputowski, and H. Jacobs, Acta Physica Polonica A 88, 5 (1995).

${ }^{9}$ J.-W. Hwang, J. P. Campbell, J. Kozubowski, S. A. Hanson, J. F. Evans, and W. L. Gladfelter, Chem. Mater. 7, 517 (1995).

${ }^{10}$ D. A. Neumayer and J. G. Ekerd, Chem. Mater. 8, 9 (1996).

${ }^{11}$ K. E. Gonsalves, G. Carlson, S. P. Rangarjan, M. Benaissa, and M. JoseYacaman, J. Mater. Chem. 6, 8 (1996).

${ }^{12}$ J. F. Janik and R. L. Wells, Chem. Mater. 8, 2708 (1996).

${ }^{13}$ J. D. Houmes and H.-C. zur Loye, Chem. Mater. 8, 2551 (1996).

${ }^{14}$ J. Karpinski, J. Jun, and S. Porowski, J. Cryst. Growth 66, 1 (1984).

${ }^{15}$ I. Grzegory, J. Jun, M. Bockowski, S. T. Krukowski, M. Wroblewski, B. Lucznik, and S. Porowski, J. Phys. Chem. Solids 56, 3 (1995).

16 S. Porowski, Acta Physica Polonica A 87, 2 (1995).

${ }^{17}$ H. Yamane, M. Shimada, S. J. Clarke, and F. J. DiSalvo, Chem. Mater. 9, 2 (1997).

${ }^{18}$ E. G. Gillan and R. B. Kaner, Chem. Mater. 8, 333 (1996).

${ }^{19}$ I. P. Parkin, Chem. Soc. Rev. 25, 3 (1996).

${ }^{20}$ J. B. Wiley and R. B. Kaner, Science 255, 1093 (1992).

${ }^{21}$ E. G. Gillan and R. B. Kaner, Inorg. Chem. 33, 5693 (1994).

${ }^{22}$ J. Gatterer, G. Dufek, P. Ettmayer, and R. Kieffer, Monatsh. Chem. 106, 1137 (1975).

${ }^{23}$ J. C. Fitzmaurice and A. Hector, Polyhedron 13, 2 (1994).

${ }^{24}$ F. P. Bundy, High Pressure Technology, edited by I. L. Spain and J. Paauwe (1977), Vol. II, p. 325.

${ }^{25}$ M. Leszczynski, T. Suski, P. Perlin, H. Teisseyre, I. Grzegory, M. Bockowski, J. Jun, S. Porowski, and J. Major, J. Phys. D 28, A149 (1995).

${ }^{26}$ B. Monemar, Phys. Rev. B 10, 2 (1974).

${ }^{27}$ R. Dingle and M. Ilegems, Solid State Commun. 9, 175 (1971).

${ }^{28}$ D. Feiler, R. S. Williams, A. A. Talin, H. Yoon, and M. S. Goorsky, J. Cryst. Growth 171, 12 (1997).

${ }^{29}$ Y. Xie, Y. Qian, W. Wang, S. Zhang, and Y. Zhang, Science 272, 5270 (1996).

${ }^{30}$ P. R. Bonneau and R. B. Kaner, Inorg. Chem. 32, 6084 (1993).

${ }^{31}$ V. L. Solozhenko, V. Z. Turkevich, and G. Will, J. Am. Ceram. Soc. 79, 2798 (1996).

AIP license or copyright, see http://apl.aip.org/apl/copyright.jsp 